\title{
REPORT
}

\section{Positive effect of predators on prey growth rate through induced modifications of prey behaviour}

\author{
Scott D. Peacor \\ Department of Ecology \\ and Evolution, University \\ of Michigan, Ann Arbor, \\ MI 48109, USA. \\ Present address: Department \\ of Fisheries and Wildlife, \\ Michigan State University, East \\ Lansing, MI 48824, USA and \\ National Oceanic and \\ Atmospheric Administration, \\ Great Lakes Environmental \\ Research Laboratory, 2205 \\ Commonwealth Blvd, Ann \\ Arbor, MI 48105, USA. \\ Tel.: +1 7347412447 . \\ Fax: +17347412055
}

\begin{abstract}
Many prey modify behaviour in response to predation risk and this modification frequently leads to a foraging rate reduction. Although this reduction can have a clear direct negative effect on prey growth rate, theory predicts that a net positive effect can occur when the combined reduction in foraging by the entire population leads to a large increase in resource level. Here, I present experimental results that corroborate this counterintuitive prediction: the predation threat of 'nonlethal' caged larval dragonflies (Anax longipes) caused a net increase in small bullfrog (Rana catesbeiana) growth. A behavioural response (i.e. a reduction in activity level and microhabitat usage) was likely to have negatively affected growth, but was offset by a positive effect on growth from a large increase in resource levels (measured using a bioassay). Further, the positive Anax effect was dependent on nutrient level, illustrating the role of the resource response magnitude. Results of this study are discussed in the context of studies in which Anax had the opposite (i.e. negative) effect on tadpole growth. Predator-induced modifications in prey behaviour can have large negative or positive effects on prey growth, the sign and magnitude of which are dependent on relative species density and resource dynamics.
\end{abstract}

\section{Keywords}

Anax, behaviourally mediated, indirect effect, nonlethal effect, phenotypic plasticity, Rana, trait-mediated, trophic cascade.

Ecology Letters (2002) 5: 77-85

\section{INTRODUCTION}

There is abundant and growing evidence that predator presence can strongly affect an organism's growth rate through the effects the predator has on the organism's phenotype (e.g. Werner et al. 1983; Van Buskirk \& Yurewicz 1998; Nakaoka 2000; Relyea 2000; McPeek et al. 2001; Peckarsky et al. 2001). This is due to an intrinsic trade-off faced by organisms while foraging: trait modifications that reduce predation risk are predicted to cause a reduction in foraging rate (Gilliam 1982; Abrams 1984, 1987; Houston et al. 1993; Werner \& Anholt 1993). Recent empirical work is demonstrating that many species from diverse taxa and disparate ecological communities respond to predators by modifying traits that determine behaviour (e.g. activity level or microhabitat preference), morphology, physiology and life history (reviewed in Lima \& Dill 1990; Kats \& Dill 1998; Lima 1998; Tollrian \& Harvell 1999). Therefore, predator effects on prey growth rate through induced modifications in prey phenotype could be widespread.
A predator-induced reduction in prey foraging rate can have two opposing effects on prey growth. Consider a three level trophic chain, in which the top, intermediate and bottom levels are termed the predator, consumer and resource levels, respectively. Consumer growth rate will be negatively affected by predator presence from predatorinduced reductions in foraging rate that come at the cost of trait-modifications used to reduce predation risk (e.g. activity level reductions and shifts to habitat with lower resource levels). In addition, a predator-induced reduction in consumer foraging rates will be likely to have an indirect positive effect on resource levels (Turner \& Mittelbach 1990; Huang \& Sih 1991; McIntosh \& Townsend 1996; Beckerman et al. 1997; Turner 1997; Peckarsky \& McIntosh 1998; reviewed in Werner and Peacor, unpublished manuscript) that could potentially reflect back and positively affect consumer growth. That is, individual foraging rates are reduced in predator presence, but the combined effect of the reduced foraging of the entire group leads to an increase in resource levels that can positively affect individual growth. 
These opposing effects of the predator-induced traitmodifications on consumer growth will hereafter be termed the direct negative and indirect positive effect of the predator.

The net effect on consumer growth rate of predatorinduced reductions in consumer foraging rates can potentially be negative or positive depending on the relative contribution of the direct negative and indirect positive effects. Several studies have shown how predator presence can lead to a reduction in prey growth rate, indicating that the negative effect was stronger than the opposing indirect positive effect (e.g. Werner et al. 1983; Van Buskirk \& Yurewicz 1998; Nakaoka 2000; Relyea 2000; McPeek et al. 2001; Peckarsky et al. 2001). However, given the nonlinear relationship between resource growth rate (population or somatic) and resource levels, a reduction in the consumer foraging rate can potentially cause a proportionately larger increase in resource level. In such a case, the indirect positive effect will be larger than the negative direct effect and we arrive at the counterintuitive prediction that the predator can have a net positive effect on consumer growth rate by inducing a reduction in consumer foraging rate (Abrams 1987, 1992; Abrams \& Rowe 1996; Diehl et al. 2000). In this scenario, the predator presence effectively reduces the rapid foraging rates used to optimize individual fitness that can overexploit resources and cause low growth rates, to lower foraging rates with proportionately higher resource levels that can sustain higher consumer growth. The magnitude of the indirect positive effect will be a function of prey density and the functional relationship between resource growth rate and resource level (Fig. 1). If resource level is high and primarily limited by intraspecific competition then a foraging reduction will not have a large effect on resource levels (Fig. 1a). In contrast, if resource level is low and primarily limited by predation (including herbivory) then a foraging reduction can have a large indirect positive effect on resource level (Fig. 1b). The magnitude of the resource response to reduced foraging, and therefore of the indirect positive effect, will also be determined by factors such as the form of the functional relationship between resource growth rate and resource level, interspecific competition for the resource, and the fraction of resource in refuges from consumption.

Theoretical analysis indicates that the indirect positive effect discussed above in relation to short-term growth rates can potentially have a large effect on population density and dynamics. For example, the net effect of a predator on prey density can be transformed from negative to positive if phenotypic responses of prey to changes in predator density are included in population models (Abrams 1987, 1992; Abrams \& Rowe 1996). The mechanism responsible for reversing the predator effect is the same as discussed above in relation to consumer growth rate. This prediction is in contrast to the traditional prediction that a predator will

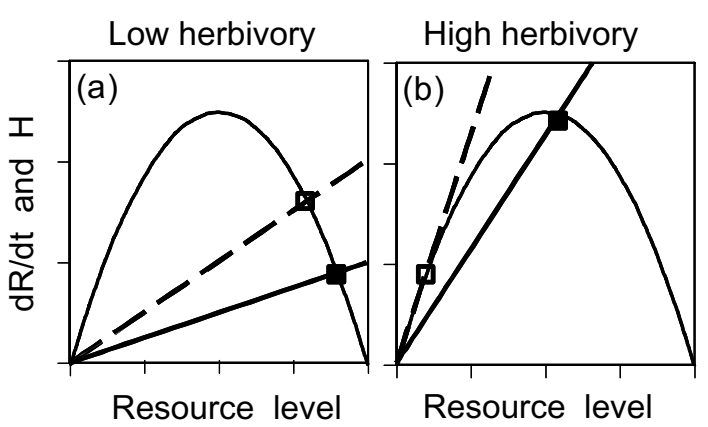

Figure 1 Effect on consumer resource levels of a predatorinduced reduction in consumer foraging rate. The parabolic curve represents the resource growth rate $(\mathrm{d} R / \mathrm{d} t)$ as a function of resource levels assuming logistic resource growth. The straight lines represent herbivory (or predation) rate, $H$, as a function of resource density (assumed linear for simplicity) in the absence (dashed lines) and presence of a 50\% reduction in herbivory (or predation) rates. If we assume constant herbivory levels and resource equilibrium, the intersection of these lines determines the resource level under different levels of herbivory. (a) At low herbivory levels, resources are primarily limited by intraspecific competition, and a reduction in herbivory has only a week effect on resource levels. (b) In contrast, at high herbivory levels, resource levels are limited primarily by herbivory. Under these conditions, a predator caused reduction in herbivory by $50 \%$ can lead to proportionately larger increase in resource levels (a $450 \%$ increase in the figure). The actual magnitude of the increase in resources will depend strongly on the form of the resource growth rate-resource level curve, the form of the herbivory-resource level curve, and other factors such as the resource refuge level and interspecific competition for the resource (see Noy-Meir (1975) for a review and discussion of the effect of reduced herbivory on resource levels under a wide range of conditions).

have a cascading negative and positive effect on prey and resources (e.g. Oksanen et al. 1981; Carpenter et al. 1987; Leibold 1996). Rather, the predator is predicted to have a positive effect on both prey and resource density.

Are indirect positive effects on a species growth, through predator-induced modifications in traits, large enough to contribute to net predator effects? Growing evidence that predators have positive trait-mediated indirect effect on resource levels through induced reductions in consumer foraging rate (reviewed in Werner and Peacor, unpublished manuscript) suggests that consequent indirect positive effects on prey growth could be widespread and important. Note, even if the net predator effect is negative, the positive component of the net predator effect could still be large and play an influential role in determining species growth rates, abundance and dynamics. In this paper, I present empirical work demonstrating a predator-induced reduction in consumer foraging rates can cause an increase in consumer growth rate through the mechanisms presented above. The 
net predator effect on consumer growth varied as a function of nutrient level, which was manipulated to help elucidate the underlying mechanisms of the predator effects and to illustrate the role of the resource response to a consumer foraging reduction. Results of this study are discussed in the context of previous studies in which predator presence had a net negative effect on consumer growth.

\section{METHODS}

I examined the effect of a 'nonlethal' predator on consumer growth (i.e. in which predators cannot kill consumers but there is perceived predation threat). By isolating nonlethal effects from density effects (i.e. predation), observed predator effects can be attributed to predator-induced effects on consumer traits. In particular, I examined small bullfrog tadpole growth (Rana catesbeiana) in presence and absence of caged larval dragonfly predators (Anax longipes) in mesocosms (Fig. 2). Small bullfrog tadpoles respond to chemical cues produced by Anax by reducing time active and changing microhabitat usage (e.g. Werner 1991; Peacor \& Werner 1997; Relyea \& Werner 1999), both of which represent a reduced foraging rate. In order to shed insight into mechanisms underlying the effects of Anax, I manipulated nutrient levels in an attempt to create different resource responses to tadpole foraging rate reductions. This also allowed for a test of the predicted role of the resource response magnitude on the nonlethal predator effect. The design was therefore a $2 \times 3$ factorial design and was replicated four times for a total of 24 mesocosms.

The study was performed at the University of Michigan's E. S. George Reserve in southern Michigan using experimental pond mesocosms designed to mimic natural ponds.

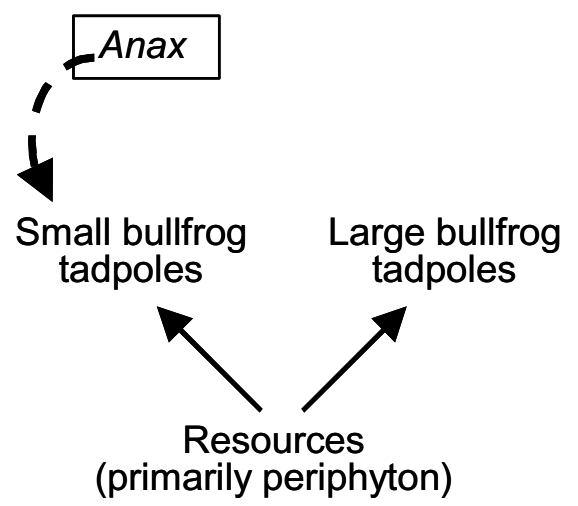

Figure 2 The experimental food web. Solid arrows represent predation and point in the direction of energy flow. The experiment was designed to test if an Anax-induced modification in small tadpole traits associated with reduced foraging rates (represented by the dashed arrow) can have a net positive effect on small tadpole growth.
Black polyethylene cylindrical cattle watering tanks $1.9 \mathrm{~m}$ in diameter were filled with $1300 \mathrm{~L}$ of well water. Each mesocosm received $6 \mathrm{~g}$ of rabbit chow as an initial tadpole resource and $300 \mathrm{~g}$ of dry oak leaves (Quercus spp.) as a substrate for periphyton and to provide structural complexity. The oak leaves and rabbit chow also provided nutrients that enhance periphyton growth. I inoculated each mesocosm with phytoplankton, periphyton and zooplankton collected from a local pond. I covered the mesocosms with green shade cloth (reducing light levels by 60\%) to deter oviposition and colonization by aquatic insects, and to reduce temperature fluctuations. Each mesocosm received four small cylindrical predator cages (positioned next to tank walls, near the water surface, and symmetrically around the tank) constructed from slotted plastic drainpipe with ends enclosed by fibreglass window screening.

I collected bullfrog eggs at the Saline Michigan Department of Natural Resources site. After growing to an average size of $10 \pm 2.5 \mathrm{mg}$ (raised on rabbit chow) in wading pools, 180 small bullfrogs were added to each mesocosm. This density of tadpoles was chosen, based on previous experiments (e.g. Peacor \& Werner 2000), to ensure moderate tadpole growth in the presence of relatively high competition for resources. When small bullfrogs were added there was a uniform layer of their periphyton resources (primarily green algae and diatoms) on tank walls and leaf surfaces. Tadpoles were allowed to acclimate and grow for 10 days (reaching an average mass of $140 \mathrm{mg}$ ) at which point (2 July) treatments were instituted. On this date, I added one Anax to each predator cage (for a total of four Anax per mesocosm) in half of the 24 mesocosms.

To manipulate resource nutrient levels, $0, \mathrm{X}$ and $2 \mathrm{X}$ of nitrogen $\left(X=0.967 \mathrm{mmol} \mathrm{m}^{-3}\right.$ of $\mathrm{N}$, in the form of $\mathrm{NH}_{4} \mathrm{NO}_{3}$ ) and phosphorus $\left(\mathrm{X}=0.076 \mathrm{mmol} \mathrm{m}^{-3}\right.$ of $\mathrm{K}$, in the form of $\mathrm{KH}_{2} \mathrm{PO}_{4}$ ) were added to each mesocosm daily starting when treatments were instituted (2 July). Previous experiments in similarly constructed mesocosms showed that these nutrient addition levels (i.e. c. X) lead to an increase in periphyton levels that can cause a substantial increase (c. 50-100\%) in tadpole growth rate (Peacor, unpublished data).

I estimated resource availability in order to elucidate mechanisms underlying caged Anax effects. The reduction in density of the most edible forms of periphyton (e.g. large diatoms) by tadpole grazing can lead to large biomass increases of less edible forms (Kupferberg 1997; Peacor unpublished). Resource biomass as determined by chlorophyll a or dry mass quantification can therefore actually be a misleading metric of tadpole resource levels. I therefore used large bullfrog tadpole growth as a bioassay of small tadpole resource levels (Fig. 2). Large bullfrog tadpoles eat similar resources as small bullfrog tadpoles in the mesocosms, but they react much less (if at all) to caged Anax (see below). Thus, 
large bullfrog growth reflects the amount of resources available to small bullfrogs within the same mesocosm. I therefore added 5 large bullfrogs (average mass $1.8 \pm 0.25 \mathrm{~g}$ ), collected at the same site as the eggs, to each mesocosm at the start of treatment manipulations (2 July). This low density minimized the potential impact of large bullfrogs on interactions between small bullfrogs and resources.

I performed observational measurements to examine how caged Anax and nutrient level affected small and large tadpole behaviour. To quantify tadpole behaviour I recorded the number of tadpoles above the tank floor, and the number of tadpoles active above the tank floor (swimming or feeding vs. inactive on tank walls). For each observational period, 6 to 10 observations for each mesocosm were made approximately every $45 \mathrm{~min}$, and averaged to yield a single measurement of the response for each mesocosm. Measurements were made on 7 July in the afternoon for small bullfrogs at all three nutrient levels, and on 9 July in the afternoon, July 10 before dawn (with a dim headlamp), and July 10 in the afternoon for small and large bullfrogs at the intermediate nutrient level.

Tadpoles were allowed to grow for 15 days after which 20 small tadpoles and all large tadpoles were removed from the mesocosms, weighed, and returned to the mesocosms. The six treatments presented here are a subset of a larger experimental design (15 treatments) that also explored the relative contribution of nonlethal and lethal predator effects (Peacor \& Werner 2001). This larger experiment was conducted until 29-30 July, at which point all tadpoles were removed and weighed. Tadpole growth, however, slowed in the latter part of the experiment (especially in the low nutrient treatment) presumably due to increased pressure on resources as tadpoles became larger. Here, I present only growth results of 17 July for clarity, although results from 29-30 July yield the same general conclusions.

\section{STATISTICAL ANALYSIS}

I used resampling techniques to test if caged Anax had a statistically significant positive effect on large bullfrog growth (i.e. final mass minus initial mass), and whether nutrient level affected the relative effect of caged Anax. I used resampling techniques because tests of biological meaningful interactions between two factors using conventional statistics such as ANOva can be problematic (Wade 1992; Wootton 1994). Because the main effect of nutrient on growth was not of interest, could be nonlinear, and could confound analysis of the relative effect of Anax at different nutrient levels, I factored out any potential main effects of nutrient level by dividing the average large bullfrog growth in each mesocosm by mean growth for all eight mesocosms within the same nutrient level. This procedure yielded 24 normalized measurements of large bullfrog growth, here- after termed the 'growth response'. I then quantified the Anax effect on growth by calculating the difference in the average growth response in the 12 Anax-present mesocosms from the average growth response in the 12 Anax-absent mesocosms. I compared the magnitude of this 'actual' Anax effect to the magnitude of 10000 identically calculated 'simulated' Anax effects computed from data in which the 24 growth responses were randomly assigned to the 24 mesocosms. The fraction of simulated Anax effects that was greater than the actual Anax effect is the $P$-value of this analysis. If less than 0.05 of the simulated Anax effects were larger than the actual $A$ nax effect (i.e. $P=0.05$ ), then $A$ nax was considered to have a significant positive effect on large bullfrog growth. While this analysis tested for an overall effect of Anax, a similar analysis, using only the responses from eight mesocosms within a nutrient treatment, was also performed to test whether Anax affected large bullfrog growth at each nutrient level. Identical analyses of an Anax effect were also performed on small bullfrog growth and small bullfrog behavioural responses measured on 7 July.

I used the same growth response to test whether caged Anax had a significantly different effect on large bullfrog growth at different nutrient levels. At each nutrient level, I defined the caged Anax effect as the difference in average growth (averaged over the four replicates) in presence and absence of caged Anax. I tested whether the difference in this predator effect between two nutrient levels (for all three nutrient pairs) was significantly different than zero by comparing it to 10000 calculations of the difference using the 12 growth responses in Anax presence randomly assigning to each of the 12 Anax-present mesocosms, and the 12 growth response in Anax absence randomly assigning to each of the 12 Anax-absent mesocosms. If less than 0.05 of the absolute value of the simulated differences was larger than the absolute value of the 'actual' difference, then Anax was considered to have had a significantly different effect at the two nutrient levels. (Because there was no a priori prediction as to which nutrient level would yield the larger predator effect, it was necessary to take the absolute value of the difference of the predator effects at the two nutrient levels.)

I performed similar analyses to examine if Anax had a differential effect on small bullfrog growth and small bullfrog behavioural responses at different nutrient levels. However, for small bullfrog growth, there was an a priori prediction that Anax would have a larger positive effect under conditions in which it had a larger positive effect on resource levels as indicated by large bullfrog growth. I thus compared only nutrient treatments in which Anax affected large bullfrog growth significantly differently. Further, it was not necessary to take the absolute value of the difference in Anax effect at different nutrient levels, as the sign of the difference was predicted from large bullfrog growth results. 
There was no statistical test performed on the caged Anax effect on the behavioural responses of the small and large bullfrogs measured on 9-10 July, as relevant results were overwhelmingly large. To insure that there were no confounding effects of tadpole mortality on tadpole growth, I performed an ANOVA on the percentage of surviving tadpoles recovered on 29-30 July. This data was arcsine transformed in order to meet assumptions of normality. There were no confounding effects of large bullfrog mortality as all except one survived.

\section{EXPERIMENTAL RESULTS}

Caged Anax had a significant positive effect on overall small bullfrog and large bullfrog growth (Table 1a); small bullfrogs grew, on average, 26\% larger in caged Anax presence, while large bullfrogs grew 250\% larger (Fig. 3). Large bullfrogs grew, on average, approximately 100\%, 700\% and $250 \%$ more at X0, X1 and X2, respectively (Fig. 3a), and this represented a significant positive effect at X1 and X2 (Table 1a). The effect of caged Anax on large bullfrog growth was significantly larger at $\mathrm{X} 1$ than $\mathrm{X} 0$, but not between X2 and X0 or between X2 and X1 (Table 1b). Small bullfrogs grew at approximately the same rate in presence and absence of Anax at X0, but $50 \%$ and $40 \%$ larger at X1 and X2, respectively (Fig. 3b). This positive effect was significant at $\mathrm{X} 1$, but marginally insignificant at X2 (Table 1a). Moreover, the effect of Anax was significantly different at different nutrient levels, as there was a larger effect on small bullfrog growth at X1 than at X0 (Tabel 1b). These growth results were unlikely confounded by mortality, as tadpole survivorship was high $(84 \%$ on average) and there was no effect of caged $\operatorname{Anax}(P=0.97)$ or nutrient level $(P=0.17)$ on small bullfrog survival.
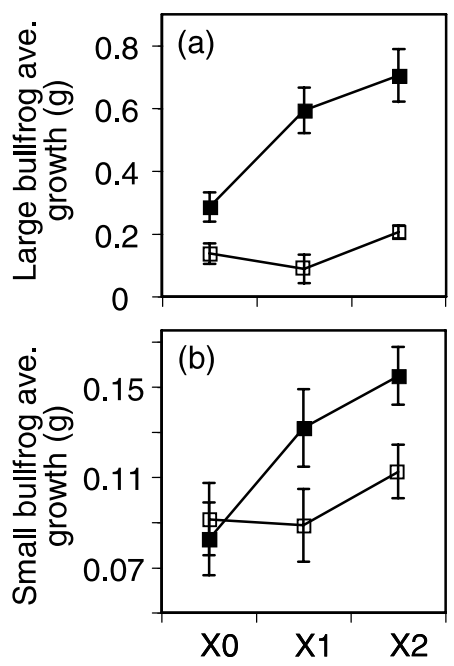

Figure 3 Average growth (initial mass minus final mass) of (a) large and (b) small bullfrogs, at low (0X), intermediate (1X) and high $(2 \mathrm{X})$ nutrient levels, and with $(\square)$ and without $(\square)$ caged Anax. Errors bars represent the standard error of four replicates.

Anax had a strong effect on small bullfrog behaviour (Figs 4 and 5). In presence of Anax there were fewer small bullfrogs above the tank floor and fewer small bullfrogs active above the tank floor. This effect was clearly much larger during the day than at night. In contrast, caged Anax had a very weak (if any) effect on large bullfrog behaviour (Fig. 4). Analysis of observational measurements performed 7 July at all nutrient levels indicated that Anax did not have significantly different effect on tadpole behaviour at the different nutrient levels (Table 1b). However, there is a trend in the data (Fig. 5) suggesting that Anax had a weaker
Table $1 P$-values of the random sampling analysis of (a) caged Anax effect, and (b) differential caged Anax effect at different nutrient levels on large bullfrog growth (final minus initial average mass), small bullfrog growth, and small bullfrog behavioural responses (number above the tank floor and number active above the tank floor measured on 7 July). For small bullfrogs, the differential effect was only analysed where results of the large bullfrog results suggested Anax could have a positive effect according to the hypothesized mechanism (see text). Therefore, a statistical analysis was not performed on the differential caged Anax effect between X0 and X2, and X1 and X2 and marked with not applicable (n.a.) in the table. (a)

\begin{tabular}{lclcc} 
& Overall effect & X0 & X1 & X2 \\
\hline $\begin{array}{l}\text { Large bullfrog growth } \\
\text { Small bullfrog growth }\end{array}$ & 0.0001 & 0.065 & $<0.0001$ & 0.006 \\
$\begin{array}{l}\text { Number small bullfrogs } \\
\text { above tank floor }\end{array}$ & 0.044 & 0.68 & 0.030 & 0.063 \\
$\begin{array}{l}\text { Number small bullfrogs active } \\
\text { above tank floor }\end{array}$ & 0.0002 & 0.148 & 0.004 & 0.013 \\
\hline
\end{tabular}

(b)

\begin{tabular}{|c|c|c|c|}
\hline & $\mathrm{X} 0$ vs. X1 & $\mathrm{X} 0$ vs. $\mathrm{X} 2$ & $\mathrm{X} 1$ vs. $\mathrm{X} 2$ \\
\hline Large bullfrog growth & 0.019 & 0.22 & 0.26 \\
\hline Small bullfrog growth & 0.041 & n.a. & n.a. \\
\hline $\begin{array}{l}\text { Number small bullfrogs } \\
\text { above the tank floor }\end{array}$ & 0.098 & 0.24 & 0.62 \\
\hline $\begin{array}{l}\text { Number small bullfrogs active } \\
\text { above tank floor }\end{array}$ & 0.68 & 0.94 & 0.74 \\
\hline
\end{tabular}



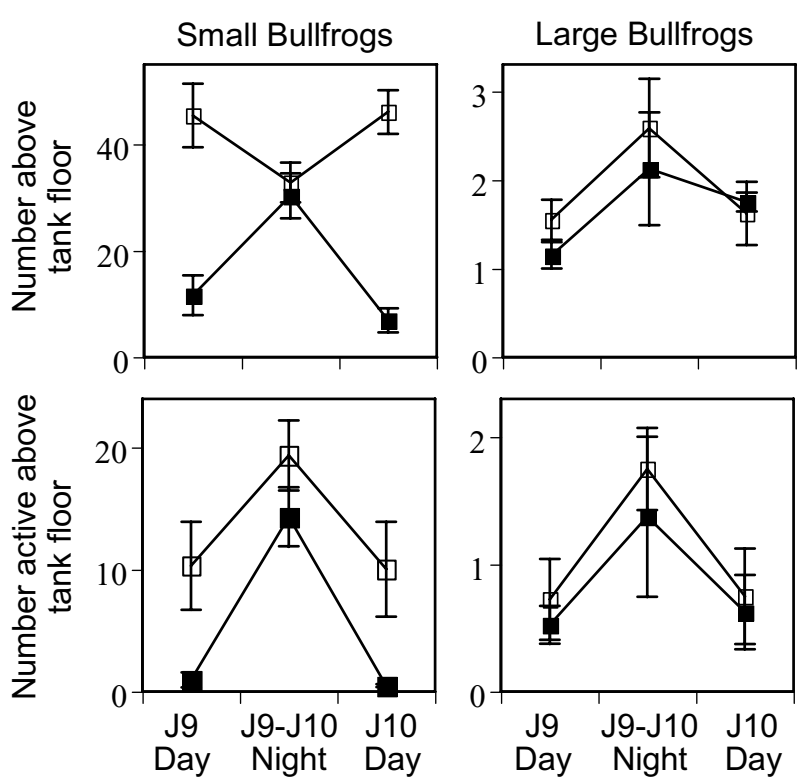

Figure 4 Small and large bullfrog behaviour during the day and night at the intermediate nutrient level. Symbols and error bars as in Fig. 3. Top panels: number of tadpoles above the tank floor. Bottom panels: number of active tadpoles (i.e. those swimming or feeding) above the tank floor.

effect on microhabitat use (i.e. number above the tank floor) at $\mathrm{X} 0$ than at the two higher nutrient levels.

\section{DISCUSSION}

The principal result of this study is that caged 'nonlethal' Anax had an indirect positive effect on small bullfrog growth. The proposed mechanism behind this counterintuitive result was further supported. In the presence of Anax, two opposing effects were evident. First, trait changes associated with reduced foraging rates were observed; in the presence of Anax, tadpoles were less active-a measure that quantifies time spent feeding and time spent swimming (presumably searching for high quality resource patches). Further, in presence of Anax, small bullfrog microhabitat shifted to a larger fraction of time on the tank floor with less time foraging on tank walls. Second, there was an indirect positive effect of Anax on resources available to small bullfrogs. Large bullfrogs reacted very little, if at all, to the presence of Anax and thus the observed higher large bullfrog growth in the presence of Anax indicates higher resource availability. On average, the indirect positive effect on small bullfrog growth was greater than the direct negative effect, causing a net positive effect.

Analysis of the differential effects of caged Anax at different nutrient levels lends further support to the hypothesized mechanism underlying the overall positive effect on small bullfrog growth. At X0, the indirect positive effect of Anax on tadpole resources, as indicated by large
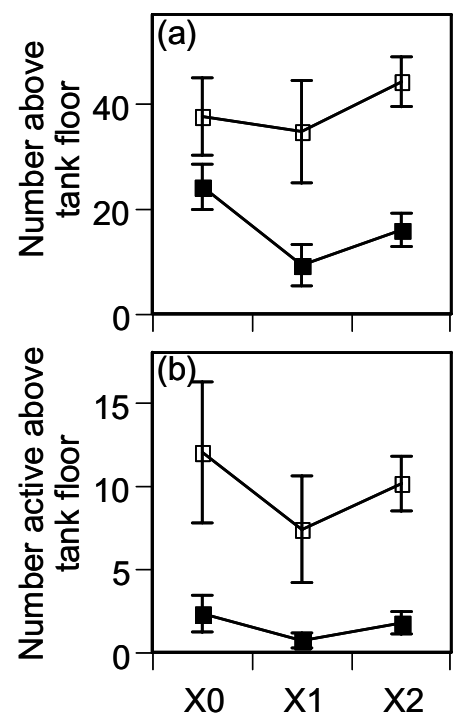

Figure 5 Effect of caged Anax on small bullfrog behaviour at three nutrient addition levels. Symbols and error bars as in Fig. 3. (a) Number of small tadpoles above the tank floor. (b) Number of small tadpoles active above the tank floor.

bullfrog growth, was much lower than at X1. If an indirect positive effect on resource level was responsible for the positive effect on small bullfrog growth, then we would predict a larger positive effect of Anax on small bullfrog growth at $\mathrm{X} 1$ than at $\mathrm{X} 0$, as observed. Apparently, at the lowest nutrient addition level (X0) strong negative and indirect positive effects counterbalanced each other to yield a negligible net effect of the caged Anax on small tadpole growth. In contrast, at the higher nutrient addition levels, the indirect positive effect offset the negative effect, for a net positive effect of the caged Anax on small tadpole growth.

The larger indirect effect of Anax on resources at X1 than at X0 was likely to be due to a steeper response of periphyton growth when Anax reduced tadpole foraging. Further, although not statistically significant, a trend in the behavioural data suggests small bullfrog tadpoles reacted less to Anax at X0 (Fig. 5). Indeed, a weaker behavioural response at lower resources is predicted by theory (Gilliam 1982; Abrams 1984, 1987; Houston et al. 1993; Werner \& Anholt 1993), and has been demonstrated empirically for tadpoles (Anholt \& Werner 1995; Peacor \& Werner 1997; Relyea 2002). It is therefore plausible that further behavioural measurements may have shown that the observed trend was significant, and this also would contribute to a smaller effect of Anax on resource levels at X0. (Note that the indirect effect of caged Anax on resource levels, as indicated by large bullfrog growth, at X2 was intermediate between that at X0 and X1. It is difficult to predict a priori how nutrient level will influence the predator effect, as many factors including the functional form of the resource growth 
rate-resource level relationship and the relative level of herbivory will affect the magnitude and direction of the effect. Further, prediction concerning periphyton responses to herbivory reduction is difficult because periphyton is composed of multiple species that are differentially sensitive to nutrient levels and nutrient ratios. The use of several nutrient levels in this experiment therefore served to produce different resource responses to tadpole foraging reduction, but I could not predict how they would be different quantitatively or even qualitatively.)

There are two potential alternative mechanisms that could contribute to the overall positive effect Anax had on small tadpole growth. First, because caged Anax were fed small tadpoles, nutrients excreted by Anax could facilitate periphyton growth, and hence tadpole growth. I have, however, tested for this process in several experiments performed in similar mesocosms and never found significant effects, and certainly no effects that could account for the large increases observed here (Peacor, unpublished data). Moreover, we would expect this mechanism to be pronounced most strongly at low nutrient addition levels, but it was at X0 that Anax had no net positive effect. Second, Anax-induced reduction in tadpole activity levels could lower the metabolic loss of tadpoles, leaving more energy to invest in growth. However, several experiments (Peacor, unpublished data) that have examined tadpole growth in mesocosms similar to those used here, but in which resource level was controlled by using artificial resources, have shown that metabolic losses are small at the growth rates exhibited in the present experiment. There are also a number of laboratory experiments that demonstrate that if tadpoles are fed an equal low food level they grow at the same rate even with very large predator-induced activity reductions (Skelly \& Werner 1990; Relyea 2001; Relyea 2002). This is expected if metabolic losses associated with activity differences are negligible because tadpoles garner the same amount of resources in presence and absence of predator-induced activity reductions when resource levels are low and resources are easily accessible in the containers used in laboratory experiments. Thus, it is unlikely that growth increases due to reduced metabolic losses could be responsible for the large growth increase seen (e.g. $50 \%$ increase at $\mathrm{X} 1$ in spite of reduced foraging) in the presence of Anax in the present experiment. Therefore, while these two mechanisms could contribute to the positive effect of the predator, I believe their contribution is small.

The potential for the nonlethal predator effect on prey growth to be negative, nonexistent or positive underscores the importance of considering the resource response when examining such effects. The negative effect on growth of reduced foraging rate can be offset by a large indirect positive effect, as demonstrated in this experiment, or overwhelm the indirect positive effect, as demonstrated in a number of other studies (e.g. Werner et al. 1983; Van Buskirk \& Yurewicz
1998; Nakaoka 2000; Relyea 2000; McPeek et al. 2001; Peckarsky et al. 2001). For example, in an experiment performed in similarly constructed mesocosms but with lower tadpole densities, caged Anax had a similar strong negative effect on small bullfrog activity and microhabitat usage as that seen in the present experiment (Peacor \& Werner 2000; data at low green frog tadpole density). In contrast to the present experiment, however, the reduced foraging rate had little effect on resource levels because tadpole density was low. Therefore the negative direct effect of caged Anax on small bullfrog growth strongly offset any indirect positive effects.

Even if the net effect of a predator on its prey through induced trait-modifications is negative or nonexistant, however, the indirect positive effect may be influential by opposing the direct negative effect of the predator. For example, at low nutrient level in this study, we might naively assume that equal growth rates of small bullfrogs in presence and absence of Anax indicate that Anax had no effect, when in fact there were likely to be large opposing negative and positive effects. This may also be the reason why Turner \& Mittelbach (1990) did not observe a nonlethal effect of bass on bluegill growth when there was a large nonlethal indirect effect of bass on bluegill resources. Recognizing this 'hidden' positive effect in such systems is important for understanding the underlying mechanisms affecting nonlethal predator effects and for representing predator effects in models.

There is an important conceptual difference between the positive effect of the predator on consumers described here, and positive effects of predators on consumers through different mechanisms presented elsewhere. Other studies have shown that a predator can have a positive effect on consumer growth by reducing the density of intra- or interspecific competitors (e.g. Paine 1966; Wilbur 1988) or predators (Oksanen et al. 1981; Carpenter et al. 1987; Schoener 1993; Menge 1994) of the consumers, or by reducing the foraging rates of interspecific competitors or predators of the consumers (reviewed in Werner and Peacor, unpublished manuscript). In all of these cases, the predator has an indirect positive effect on a subset of organisms that arises from a negative effect (death or reduced foraging rates) of the predator on another subset of organisms. In contrast, in the present study, predators inhibit a negative effect the consumers cause (as a collective group) on their own growth. Individual consumers forage at a rate that benefits individual fitness, but as a collective group this rate can reduce the density and/or productivity of their resources to low levels, i.e. they 'overexploit' (sensu Abrams 1987) or 'overgraze' (sensu Noy-Meir 1975) the resource. The presence of the predator in this study acted to shift the foraging strategy of the individual to one in which the collective effect on resources is less severe, and consequently led to higher density and/or productivity of the resource and therefore 
positively affected consumer growth. This positive effect on consumer growth is similar to that seen in the management of livestock, in which human control of livestock foraging causes a positive effect on growth compared to unrestrained foraging, through positive effects on resource production.

The two key processes that led to the indirect positive effect of the predator on prey growth in this experiment are common in diverse natural systems, and thus may be influential in natural systems. First, tadpoles responded to Anax by modifying phenotype in a manner that reduced foraging rate. This has been demonstrated for many species representing diverse taxa (reviewed in Lima \& Dill 1990; Kats \& Dill 1998; Lima 1998; Tollrian \& Harvell 1999). Second, the tadpoles reduced resource levels to low enough densities that the predator-induced reduction in foraging rates was met by a positive resource growth response. This can occur whenever predation (including herbivory) plays an influential role in limiting resource growth (as opposed to resources being limited strictly by 'bottom up' factors), a process that commonly occurs in both terrestrial and aquatic systems (see, e.g. Huntly 1991; Carpenter \& Kitchell 1993; Leibold et al. 1997). The necessary mechanisms for the indirect positive effect of the predator are thus satisfied, and there is therefore reason to believe the predator effects on prey growth demonstrated here can occur in diverse natural systems. While I have examined the predator-consumer -resource chain in terms of three species, the same processes could be important in systems in which multiple species at the consumer trophic level modify traits to reduce predation risk from multiple predators.

In conclusion, this study adds to growing evidence that effects of predator-induced modification in prey traits can play a large role in determining the effect of predation in ecological communities. Historically, ecologists have focused on density effects when examining the potential importance of species interactions in determining abundance and dynamics of species. Recently, however, ecologists examining diverse systems are demonstrating that the underlying mechanisms that can cause trait-mediated effects are ubiquitous, and ecologists are increasingly demonstrating that trait-mediated effects can play a large role in structuring ecological communities. Here, I have shown a rather counterintuitive consequence of predator-induced effects on prey traits, i.e. that a positive effect on prey growth can result. It is plausible that predators in natural systems can have an indirect positive effect on their prey through the mechanisms outlined here, and that the general mechanisms could operate in systems with multiple species within trophic levels. Even if the indirect positive effect simply opposes (rather than offsets as demonstrated here) the direct negative effect of a predator-induced reduction in prey foraging, it still can be an important mechanism contributing to the net effects of a predator on its prey.

\section{ACKNOWLEDGEMENTS}

I thank Bob Rommel, Chad Walasek and Earl Werner for their help in conducting the experiment and Donald Schoolmaster for help with statistical analysis. Comments by Carlos Bernstein, Spencer Hall, Doran Mason, Peter McIntyre, Cathy Pfister, Luis Schiesari, Marcel Visser, Earl Werner, Tim Wootton and an anonymous referee have greatly improved the manuscript. I thank James Gapczynski and Allan Sutton for permission to collect and help in collecting specimens at the Michigan Department of Natural Resources Saline Pond Facility. This work was supported by NSF grant DEB 9615523.

\section{REFERENCES}

Abrams, P.A. (1984). Foraging time optimization and interactions in food webs. Am. Naturalist, 124, 80-96.

Abrams, P.A. (1987). Indirect interactions between species that share a predator: varieties on a theme. In: Predation: Direct and Indirect Impacts on Aquatic Communities, eds Kerfoot, W.C. \& Sih, A. University Press of New England, Hanover, pp. 38-54.

Abrams, P.A. (1992). Why don't predators have positive effects on prey populations? Evol. Ecol., 6, 449-457.

Abrams, P.A. \& Rowe, L. (1996). The effects of predation on the age and size of maturity of prey. Evolution, 50, 1052-1061.

Anholt, B.R. \& Werner, E.E. (1995). Interaction between food availability and predation mortality mediated by adaptive behavior. Ecology, 76, 2230-2234.

Beckerman, A.P., Uriarte, M. \& Schmitz, O.J. (1997). Experimental evidence for a behavior-mediated trophic cascade in a terrestrial food chain. Proc. Natl Acad. Sci. USA, 94, 10735-10738.

Carpenter, S.J. and Kitchell, J.F. (1993) The trophic cascade in lakes. Cambridge University Press, Cambridge, UK.

Carpenter, S.R., Kitchell, J.F., Hodgson, J.R., Cochran, P.A., Elser, J.J., Elser, M.M., Lodge, D.M., Kretchmer, D., He, X. \& Vonende, C.N. (1987). Regulation of lake primary productivity by food web structure. Ecology, 68, 1863-1876.

Diehl, S., Cooper, S.D., Kratz, K.W., Nisbet, R.M., Roll, S.K., Wiseman, S.W. \& Jenkins, T.M. (2000). Effects of multiple, predator-induced behaviors on short-term producer-grazer dynamics in open systems. Am. Naturalist, 156, 293-313.

Gilliam, J.F. (1982). Habitat use and competitive bottlenecks in sizestructured fish populations. PhD Thesis, Michigan State University, Long Lasting, MI, USA.

Houston, A.I., Mcnamara, J.M. \& Hutchinson, J.M.C. (1993). General results concerning the trade-off between gaining energy and avoiding predation. Phil. Trans. R. Soc. Lond. B, 341, 375-397.

Huang, C.F. \& Sih, A. (1991). Experimental studies on direct and indirect interactions in a 3 trophic-level stream system. Oecologia, 85, 530-536.

Huntly, N. (1991). Herbivores and the dynamics of communities and ecosystems. Annu. Rev. Ecol. Syst., 22, 477-503.

Kats, L.B. \& Dill, L.M. (1998). The scent of death: chemosensory assessment of predation risk by prey animals. Ecoscience, 5, 361-394. 
Kupferberg, S.J. (1997). Facilitation of periphyton production by tadpole grazing: Functional differences between species. Freshwater Biol., 37, 146-159.

Leibold, M.A. (1996). A graphical model of keystone predators in food webs: trophic regulation of abundance, incidence, and diversity patterns in communities. Am. Naturalist, 147, 784-812.

Leibold, M.A., Chase, J.M., Shurin, J.B. \& Downing, A.L. (1997). Species turnover and the regulation of trophic structure. Annu. Rev. Ecol. Syst, 28, 467-494.

Lima, S.L. (1998). Stress and decision making under the risk of predation: recent developments from behavioral, reproductive, and ecological perspectives. Stress Behav., 27, 215-290.

Lima, S.L. \& Dill, L.M. (1990). Behavioral decisions made under the risk of predation: a review and prospectus. Can. J. Zool.-Revue Canadienne de Zoologie, 68, 619-640.

McIntosh, A.R. \& Townsend, C.R. (1996). Interactions between fish, grazing invertebrates and algae in a New Zealand stream: a trophic cascade mediated by fish induced changes to grazer behaviour? Oecologia, 108, 174-181.

McPeek, M.A., Grace, M. \& Richardson, J.M.L. (2001). Physiological and behavioral responses to predators shape the growth /predation risk trade-off in damselflies. Ecology, 82, 1535-1545.

Menge, B.A. (1994). Indirect effects in marine rocky intertidal interaction webs: pattern and importance. Ecol. Monographs, 65, 2174.

Nakaoka, M. (2000). Nonlethal effects of predators on prey populations: predator-mediated change in bivalve growth. Ecology, 81, 1031-1045.

Noy-Meir, I. (1975). Stability of grazing systems: an application of predator-prey graphs. J. Ecol., 63, 459-481.

Oksanen, L., Fretwell, S.D., Arruda, J. \& Niemela, P. (1981). Exploitation ecosystems in gradients of primary productivity. Am. Naturalist, 118, 240-261.

Paine, R.T. (1966). Food web complexity and species diversity. Am. Naturalist, 100, 65-75.

Peacor, S.D. \& Werner, E.E. (1997). Trait-mediated indirect interactions in a simple aquatic food web. Ecology, 78, 1146-1156.

Peacor, S.D. \& Werner, E.E. (2000). Predator effects on an assemblage of consumers through induced changes in consumer foraging behavior. Ecology, 81, 1998-2010.

Peacor, S.D. \& Werner, E.E. (2001). The contribution of traitmediated indirect effects to the net effects of a predator. Proc. Natl Acad. Sci. USA, 98, 3904-3908.

Peckarsky, B.L. \& McIntosh, A.R. (1998). Fitness and community consequences of avoiding multiple predators. Oecologia, 113, $565-576$.

Peckarsky, B.L., Taylor, B.W., McIntosh, A.R., McPeek, M.A. \& Lytle, D.A. (2001). Variation in mayfly size at metamorphosis as a developmental response to risk of predation. Ecology, 82, 740-757.

Relyea, R.A. (2000). Trait-mediated indirect effects in larval anurans: reversing competition with the threat of predation. Ecology, 81, 2278-2289.
Relyea, R.A. (2001). Morphological and behavioral plasticity of larval anurans in response to different predators. Ecology, 82, 541-554.

Relyea, R.A. (2002). Competitor-induced plasticity in tadpoles: consequences, cues, and connections to predator-induced plasticity. Ecology, in press.

Relyea, R.A. \& Werner, E.E. (1999). Quantifying the relation between predator-induced behavior and growth performance in larval anurans. Ecology, 80, 2117-2124.

Schoener, T.W. (1993). On the relative importance of direct versus indirect effects in ecological communities. In: Mutualisms and Community Organization, eds Kawanabe, H., Cohen, J.E. \& Iwasaki, K. Oxford University Press, Oxford, pp. 365-411.

Skelly, D.K. \& Werner, E.E. (1990). Behavioral and life-historical responses of larval American toads to an odonate predator. Ecology, 71, 2313-2322.

Tollrian, R. \& Harvell, C.D., eds. (1999). The ecology and evolution of inducible defenses. Princeton University Press, New Jersey.

Turner, A.M. (1997). Contrasting short-term and long-term effects of predation risk on consumer habitat use and resources. Behav. Ecol., 8, 120-125.

Turner, A.M. \& Mittelbach, G.G. (1990). Predator avoidance and community structure: interactions among piscivores, planktivores, and plankton. Ecology, 71, 2241-2254.

Van Buskirk, J. \& Yurewicz, K.L. (1998). Effects of predators on prey growth rate: relative contributions of thinning and reduced activity. Oikos, 82, 20-28.

Wade, M.J. (1992). Sewall Wright: Gene Interaction and the Shifting Balance Theory. In: Oxford Surveys of Evolutionary Biology $V I$, eds Antonovics, J. \& Futuyma, D. Oxford University Press, Oxford, pp. 35-62.

Werner, E.E. (1991). Nonlethal effects of a predator on competitive interactions between 2 anuran larvae. Ecology, 72, 1709_ 1720.

Werner, E.E. \& Anholt, B.R. (1993). Ecological consequences of the trade-off between growth and mortality-rates mediated by foraging activity. Am. Naturalist, 142, 242-272.

Werner, E.E., Gilliam, J.F., Hall, D.J. \& Mittelbach, G.G. (1983). An experimental test of the effects of predation risk on habitat use in fish. Ecology, 64, 1540-1548.

Wilbur, H.M. (1988). Interactions between size-structured populations: from individual behavior to ecosystem dynamics. In: Size-Structured Populations, eds Ebenman, B. \& Persson, L. Springer-Verlag, New York, pp. 157-172.

Wootton, J.T. (1994). Putting the pieces together: testing the independence of interactions among organisms. Ecology, 75, 1544-1551.

Editor, C. Bernstein

Received 23 August 2001

First decision made 10 October 2001

Manuscript accepted 12 October 2001 